\title{
Dimensões geopolíticas do modernismo. Contraculturas mexicanas na Califórnia
}

The Geopolitical Dimension of Modernism. Mexican Immigrants and Alternative Modernities

Dimensions géopolitiques du modernisme. Contre-culutres mexicaines du modernisme en Californie

Maria José Canelo

\section{CpenEdition}

\section{Journals}

Edição electrónica

URL: http://journals.openedition.org/rccs/937

DOI: $10.4000 /$ rccs.937

ISSN: 2182-7435

\section{Editora}

Centro de Estudos Sociais da Universidade de Coimbra

\section{Edição impressa}

Data de publição: 1 Junho 2006

Paginação: 115-127

ISSN: 0254-1106

\section{Refêrencia eletrónica}

Maria José Canelo, « Dimensões geopolíticas do modernismo. Contraculturas mexicanas na Califórnia », Revista Crítica de Ciências Sociais [Online], 74 | 2006, colocado online no dia 01 outubro 2012, criado a 01 maio 2019. URL : http://journals.openedition.org/rccs/937 ; DOI : 10.4000/rccs.937

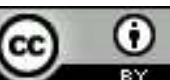




\section{Dimensões geopolíticas do modernismo. Contraculturas mexicanas na Califórnia}

Proponho-me repensar o modernismo tendo em conta a afirmação de Homi K. Bhabha de que "cada repetição do signo da modernidade é diferente, específica das suas condições de enunciação históricas e culturais". Centrando-me na obra de Carey McWilliams, procuro dar a conhecer e discutir um trabalho crítico que salienta a dimensão geopolítica do modernismo e demonstra que a modernidade não deu, de facto, origem a um tipo único de experiência nos Estados Unidos. Neste caso, o contexto da Grande Depressão, enquanto configuração histórica e cultural específica, exige uma reformulação da expressão e das formas modernistas, na medida em que torna evidente que, quando a modernização fracassa, emergem na sociedade americana fenómenos de desenvolvimento desigual que desafiam a definição de modernidade. A reflexão crítica de McWilliams antecipa configurações críticas actuais, das "contraculturas da modernidade" às "modernidades alternativas".

A proposta deste trabalho é repensar o modernismo tendo em conta a afirmação de Homi K. Bhabha de que "[c] ada repetição do signo da modernidade é diferente, específica das suas condições de enunciação históricas e culturais" (1994: 247). Penso que o contexto da Grande Depressão nos Estados Unidos, sendo um período que inverteu substancialmente aquilo que tomamos, de um modo geral, como os valores centrais da cultura desta nação, foi uma época que permitiu a muitos experimentar o reverso da modernidade e da modernização. Bhabha, como é sabido, assume uma perspectiva pós-colonial que pode parecer desajustada aqui; a não ser, talvez, que nos lembremos da história colonial, ou imperial, da única fronteira política que separa o "Primeiro" do "Terceiro" Mundos, a fronteira entre os Estados Unidos e o México. É esta fronteira que é alvo de grande parte da análise crítica aqui em discussão.

Há mais de uma década que a crítica sobre o modernismo tem vindo a chamar a atenção para a relevância de categorias sociais como a raça, o sexo, a nação, a classe, a pós-colonialidade e a sexualidade, ao mesmo tempo que assenta cada vez mais em análises interdisciplinares, o que tem permitido reconfigurar o modernismo como um campo discursivo e histórico - é nesta 
prática que se baseia grande parte da minha argumentação. Com a viragem referida, o modernismo deixou de ser entendido simplesmente como um período estético, como fora originalmente concebido, passando antes a ser encarado como um discurso que dialoga necessariamente com outros, nomeadamente, com os discursos da modernidade e da modernização. Além disso, ao analisar agora o processo de formação do conhecimento e da definição do modernismo, bem como das suas formas estéticas, não é só este diálogo que se torna objecto de estudo, mas todo o contexto histórico, cultural, social e político e a perspectiva tomada pelo próprio crítico.

Para começar, é importante que diferencie estes três termos, ainda que de forma breve: em geral, a abordagem à "modernidade", quer enquanto conceito sociológico, quer como categoria ou período estético - as duas formas mais comuns de categorização - depende da perspectiva teórica ou disciplinar. De um ponto de vista histórico, o projecto da modernidade tem as suas origens intelectuais nos filósofos iluministas, mas foi a Revolução Francesa, em 1789, que lhe atribuiu um pendor político e ideológico. Já no campo das ciências sociais, a modernidade é tomada como sinónimo do processo da industrialização, tem o seu ponto mais alto nos séculos XVIII e XIX e, naturalmente, corre em paralelo ao desenvolvimento do capitalismo. Aqui, a modernidade é criada por uma série de processos complexos e interligados que o próprio capital gera e a tecnologia, enquanto aplicação da racionalidade, é entendida como o veículo último da modernidade: a modernização corresponde justamente a este processo. Por fim, o modernismo é entendido não só como uma resposta crítica à modernização, mas também como a articulação da relação de cada indivíduo com a modernidade.

As críticas à modernidade têm salientado sobretudo a ênfase na razão, e o consequente negligenciar da subjectividade enquanto emoção, sentimento ou afecto. O estudo basilar de Horkheimer e Adorno, A dialéctica do Iluminismo, defende que a industrialização e a urbanização separaram fatalmente o indivíduo do mundo sensível, abstraindo-o de tal modo que o tornaram incapaz de recuperar a liberdade. Esta posição acerca da repressão da subjectividade é reforçada pela centralidade do estado-nação, a estrutura racionalizadora por excelência da modernidade. Ao fazer da homogeneidade e da hierarquia as suas palavras de ordem, o Estado também se tornou no mecanismo máximo de regulação da emoção e da subjectividade, ao centralizar em si próprio as solidariedades individuais, através do apelo da nação. Como escreveu Fredric Jameson, a modernidade, com a sua racionalidade excessiva, acabou por falhar na criação de significado (Jameson, 2000). O chamado modernismo de elite herdou esta preocupação com a 
racionalidade, que se torna evidente na sua teorização específica da subjectividade como "emoção destilada" ou "correlativo objectivo", para mencionar apenas dois dos mais influentes conceitos eliotianos.

Ora, as releituras do modernismo têm pesquisado justamente as formas de subjectividade omitidas no projecto do modernismo de elite. Estas reapreciações do modernismo exigem, no entanto, e antes de mais, uma historicização da subjectividade e também a sua articulação com práticas do quotidiano, outro dos aspectos rejeitados pelos modernistas e que passa a ser recuperado como o lugar onde os indivíduos, proprietários plenos do seu corpo, das suas memórias e afectos, podem construir contra-memórias, territórios de inquietude e resistência, onde o Estado disciplinador pouco ou nenhum alcance consegue ter. No seguimento desta orientação crítica, faz mais sentido retomar a teoria de Marshall Berman acerca da dialéctica da modernização, na medida em que Berman ajuda a conceber o modernismo também como uma experiência criativa:

[Os] processos históricos mundiais [a modernização] criaram uma variedade espantosa de visões e ideias que pretendem fazer dos homens e das mulheres os sujeitos e também os objectos da modernização, dar-lhes o poder de mudar o mundo que os vai mudando, atravessar o maelstrom e torná-lo seu. (Berman, 1982: 16; sublinhado meu)

As revisões da teoria da modernidade têm sido especialmente prósperas na área dos estudos pós-coloniais, que atacam o eurocentrismo dessa teoria - mais notório nas pretensões de racionalidade, universalidade e progresso -, bem como o seu racismo estruturante e, portanto, a inevitável cumplicidade da modernidade com o poder colonial. Neste aspecto, a subjectividade articula-se claramente com questões de capacidade de acção: às definições de modernidade, modernização e modernismo acima referidos, os críticos pós-coloniais acrescentam a categoria do império. Colocando a estrutura imperial na raiz da modernidade, torna-se claro que, para que certas culturas se definissem como modernas, era necessário que outras fossem definidas - e assim permaneceram muito tempo - como não-modernas ou primitivas, não-desenvolvidas ou subdesenvolvidas.

Paul Gilroy, por exemplo, demonstrou de forma cabal que a opressão, sob a forma da escravatura, era a contradição fundamental da modernidade. Para Gilroy (1993), o reverso da racionalidade era formado pelo medo e o terror, a falta de sentido e a deslocação, já que o cidadão racional só assim podia ser definido em oposição ao escravo infantilizado. A escravatura revelou, pois, a modernidade como um projecto nem de progresso, nem de 
aplicação universal. Menos ainda seria a felicidade o seu ideal de referência: a experiência do escravo revelou o terror racial como o irmão gémeo da razão na fundação da modernidade, pois o medo não era um obstáculo a eliminar, mas uma experiência constituinte da vida do escravo. Assim, a experiência e expressão da modernidade dos negros enquanto reverso da modernidade exige necessariamente uma alternativa aos paradigmas de modernidade dominantes.

Arjun Appadurai elaborou o termo geral "modernidades alternativas", ao passo que Gilroy fala das "contraculturas da modernidade", uma designação correlativa do conceito de "contraculturas pós-coloniais", de Homi Bhabha. Todas estas elaborações teóricas convergem naquilo que tem sido designado como um novo paradigma, que propõe a inserção do modernismo num diálogo com formas de experiência e de expressão da modernidade com origem em territórios não ocidentais e não centrais. Noções como "modernidades alternativas" e "contraculturas da modernidade" assinalam contradições específicas no coração da modernidade e, ao introduzir na análise outros contextos culturais e materiais, desafiam o seu universalismo. A noção de contraculturas da modernidade também salienta as respostas à modernidade que se constituem como autocríticas ou rejeições e selecções de aspectos precisos da modernidade.

Quando a Grande Depressão obrigou a sociedade americana e os seus sonhos a confrontarem-se com a pobreza maciça e o desespero, os intelectuais do movimento social que ficou conhecido como "Popular Front" procuraram novas formas de explicação e de expressão dessa nova realidade. ${ }^{2}$ Se, por um lado, estes intelectuais eram, como Michael Denning afirma, os filhos das artes modernistas, eles debatiam-se, por outro lado,

\footnotetext{
${ }^{1}$ Appadurai cunhou o conceito de "modernidades alternativas" na década de 1980, para se referir à modernidade em contextos como a Ásia, a África e a América Latina. Uma modernidade alternativa é um discurso crítico que analisa o presente recorrendo ao discurso ocidental da modernidade, mas com uma diferença, que deriva das especificidades do contexto cultural e material que acolhe o modelo da modernidade e a partir do qual ele é re-enunciado. A historicização dos contextos torna evidente que as experiências da modernidade são necessariamente múltiplas. A modernidade alternativa indica uma constelação mais vasta na qual têm lugar as práticas de contracultura. Cf. Appadurai, 1998.

2 A Popular Front foi um movimento social vasto, que emergiu da crise de 1929 e cujo projecto era a criação de uma democracia social. Frequente, mas erroneamente, identificado com o partido comunista, a Popular Front incluía membros do partido que tinham laços fortes com os sindicatos industriais, mas, segundo Denning, é mais correcto definir a Popular Front como uma aliança de esquerda ou um bloco histórico. A influência da Popular Front foi tão significativa, porque os seus membros trabalhavam na indústria e no aparelho cultural - daí também a designação "cultural front". Uma das tarefas do segmento intelectual da Frente com maior repercussão foi a tentativa de teorizar a relação da cultura com a política (Denning, 1997: xix).
} 
com a necessidade, não só de assimilar, mas sobretudo de transcender o legado modernista da experimentação formalista (1997: 29). Eram precisas novas formas de expressão, porque existia uma consciência nova dos casos de desenvolvimento desigual na sociedade norte-americana, que demonstravam que diferentes relações com as estruturas de poder produziam experiências da modernidade profundamente distintas. Como é sabido, Let Us Now Praise Famous Men, de James Agee e Walker Evans, foi uma das respostas modernistas mais conhecidas neste contexto. Os estudos de Carey McWilliams sobre as minorias étnicas da Califórnia, e os mexicanos em particular, ilustram algumas experiências profundamente diferentes da modernidade.

Advogado, escritor e activista, McWilliams conta-se entre os intelectuais da Popular Front que procuraram teorizar a relação entre a cultura e a política (Denning, 1997: xix), em parte através da sua entrega às instituições culturais e políticas do New Deal: McWilliams desempenhou o cargo de director da Comissão de Imigração e Alojamento da Califórnia, entre 1938 e 1942. O seu trabalho crítico e cultural é extenso e debruça-se sobre a história étnica do Sudoeste e, especialmente, dos grupos de língua espanhola da Califórnia - da comunidade imigrante mexicana, aos filhos desses imigrantes (os pachucos) e aos residentes dos estados anexados, como o Novo México. Estes eram os descendentes dos colonos espanhóis que se tinham tornado cidadãos automaticamente, ao abrigo do Tratado de Guadalupe-Hidalgo (1848), que pôs termo à guerra entre os Estados Unidos e o México. Tanto os imigrantes como os cidadãos americanos descendentes de mexicanos eram, todavia, discriminados em função da sua cultura, que não cumpria os requisitos de modernidade que caracterizavam a cultura dominante dos Estados Unidos.

Como estudioso de identidades, McWilliams começou por deslindar a dimensão histórica e política do problema. Na sua opinião, em primeiro lugar, o conflito cultural que marginalizava toda a comunidade de língua espanhola no Sudoeste tinha de ser contextualizado, já que a raça, a discriminação e a cultura estavam profundamente enraizadas nas circunstâncias históricas e políticas de um momento específico da história comum dos Estados Unidos e do México: o "nascimento" da sua fronteira comum.

Há, portanto, toda uma história geopolítica que complementa as ideias de McWilliams acerca da imigração. Afinal, só graças à fronteira o movimento das pessoas naquela região passara a ser definido como "imigração". McWilliams destacou o facto de o tratamento das populações de origem mexicana no Sudoeste estar ligado a uma forma de colonialismo que ele denunciava como "a eterna questão do trabalho barato e explorável" 
(1951: 341). O imperialismo era parte integrante deste quadro, na medida em que a guerra com o México fora a primeira pedra do império norte-americano. O império é, com efeito, o ponto nodal da sua discussão sobre o carácter excepcional das políticas raciais californianas para com os mexicanos e os índios.

McWilliams chamou a atenção para a manipulação dos imigrantes mexicanos. A sua exploração pelos grandes latifundiários do Oeste só era possível por os mexicanos serem um tipo específico de sujeito colonizado. Os mexicanos sofriam uma forma de opressão interna, mais informal, e, por isso, mais difícil de punir, que ele designava como "imperialismo interno" e definia assim:

A maior parte dos americanos não vê que o imperialismo pode ser de dois tipos: aquele que leva os seus processos de exploração a pátrias remotas e aquele que atrai a si povos não-industrializados, através da promessa ou esperança de um nível de vida mais alto. O último é normalmente menos brutal que o primeiro, mas é essencialmente um imperialismo interno. (1951: 130; sublinhado meu)

Daí a associação do México por McWilliams a um mercado colonial de fornecimento de mão-de-obra. O México era uma área subdesenvolvida situada na periferia de um grande sistema industrial e podia até vir a ser incorporada nesse sistema maior. Tecnicamente, os territórios anexados do Sudoeste (e mesmo o próprio México, como um reservatório sempre disponível de mão-de-obra barata) correspondiam a essa definição; os estados anexados eram "qualquer área de matéria-prima ou colonial, que pode ficar no estrangeiro ou ser localizada numa região atrasada ou desfavorecida, mas é, em termos económicos, parte do mesmo sistema industrial" (McWilliams, 1951: 325).

A fronteira, o capitalismo e os programas assimilacionistas impostos à comunidade imigrante contribuíam para segregar e desautorizar o imigrante. A hierarquia étnica em que o sistema se apoiava era preservada, para começar, através da fabricação da estranheza no local de trabalho, que mantinha os grupos separado uns dos outros. ${ }^{3}$ Esta separação era reforçada pelo modelo do trabalho sazonal e acompanhada pela segregação não oficial dos grupos étnicos nos campos agrícolas, bem como nos lugares

\footnotetext{
${ }^{3}$ A este respeito, McWilliams escreve o seguinte, em Brothers Under the Skin: "a estratificação das sociedades industriais tende a transformar em 'estranhos' pessoas que trabalham na mesma fábrica, levantam o salário no mesmo guiché e se vêm durante cinco dias por semana. Neste mundo, os grupos culturais e raciais são separados e isolados através dos mesmo processo que 'aliena' os indivíduos da ordem social." (1951:336).
} 
públicos e na habitação, que encurralava os imigrantes mexicanos nas chamadas colonias. Por tudo isto também, a integração linguística era uma falsa questão. Obviamente, todos estes mecanismos de exclusão favoreciam, entre os imigrantes, o aparecimento de modelos de comportamento orientados para a comunidade.

Era, em parte, de acordo com a hierarquia étnica estabelecida que os grupos eram considerados capazes ou não de assimilar a cultura dominante. Assim, a assimilação (na época, sinónimo de integração) também era um eufemismo para integração económica. Por esta ordem de ideias, a ideologia da assimilação era outro veículo do racismo, já que estes grupos eram considerados marginais e, no caso dos mexicanos, a marginalidade era vista como um produto da sua própria, e obstinada, ingratidão, pela sua recusa da cultura dominante. A discriminação era por isso sancionada pela opinião pública, mesmo que o isolamento da comunidade mexicana derivasse, na verdade, de uma efectiva falta de escolha.

Era, aliás, fácil manter este isolamento, dado o modelo peculiar de imigração mexicana. Não apenas a proximidade da fronteira, mas também a transparência efectiva desta barreira artificial, permitia aos mexicanos cultivar com facilidade as suas formas de vida e as suas tradições: "os mexicanos, quando se deslocavam para 'norte do México', sentiram sempre que se estavam a movimentar num ambiente conhecido, em termos geográficos, culturais e históricos. Eles não atravessaram um oceano para uma terra nova e completamente desconhecida." (Williams, 1970: 4).

Esta faceta da imigração mexicana também explicava o fracasso dos programas de assimilação aplicados ao grupo, os chamados programas de americanização. Como McWilliams afirmava:

A maior parte dos americanos aprendeu a pensar na imigração como um processo através do qual os europeus pegaram em malas e bagagens e vieram "para estas margens". Do ponto de vista do imigrante, a travessia atlântica era da maior importância psicológica e sociológica; era um rompimento, um cruzamento, uma transição abrupta. Mas os imigrantes mexicanos raras vezes se aventuraram além do leque de influência hispana nos territórios de fronteira. Eles foram levados às terras de fronteira por um sentimento de continuidade, de transição gradual, de movimento entre os limites e o manto protector de um ambiente conhecido. [...] Ao migrarem para as borderlands, os mexicanos não fundaram propriamente colónias de imigrantes, o que fizeram foi "ir viver para casa de familiares". Com efeito, os seus parentes e familiares estão espalhados por todo o percurso. [...] Os anglo-americanos emigram para o México; mas nenhum mexicano é verdadeiramente um "imigrante" no Sudoeste. (McWilliams,1968: 58-59) 
A conclusão era fácil de tirar: "o mexicano, no Sudoeste, nunca se deixará assimilar da mesma forma que os outros grupos imigrantes foram assimilados [...] eles [os mexicanos] pertencem ao Sudoeste, onde, ao longo do tempo, sobreviveram vestígios importantes da sua cultura" (McWilliams, 1946: 320-321).

$\mathrm{Na}$ altura em que McWilliams escrevia, a comunidade de língua espanhola no Sudoeste já contava dois milhões de pessoas, entre imigrantes e cidadãos. Mas os imigrantes eram as vítimas deste sistema de castas bem organizado, que se auto-perpetuava, condenando-os a formas diversas de discriminação: "[o sistema] condenava-os a formas de emprego restritivas, impunha-lhes um sistema de discriminação social complexo e abrangente e criava um desajustamento crónico" (McWilliams, 1951: 66). Ao mesmo tempo, os imigrantes eram continuamente apontados como culpados por este desajuste na integração, tornando-se objecto dos programas de americanização que tentavam eliminar as suas culturas de origem, convertendo as culturas populares na cultura moderna dos Estados Unidos. Estes programas mediam as capacidades de aprendizagem do inglês e procuravam transformar os valores de acordo com a norma cultural da sociedade norte-americana, que incluía valores como a ordem, o governo e o Direito, o patriotismo e a submissão aos símbolos americanos (Gonzalez, 1997: 161). A natureza destes valores sugere que a assimilação dos imigrantes mexicanos seguia um padrão ordeiro, que visava colocá-los nas classes mais baixas da escala social e cujo objectivo último era, naturalmente, fazer dos imigrantes trabalhadores dóceis, uma condição da sua integração futura.

Os valores e tradições que alimentavam culturalmente estas comunidades eram considerados obstáculos à integração. A cultura dos imigrantes e a dos norte-americanos situavam-se em pólos opostos: uma cultura popular e uma cultura industrial moderna. Como afirma o crítico chicano Gilbert Gonzalez, os sociólogos desta época tendiam a ver a cultura popular como uma ameaça à existência e ao desenvolvimento da cultura moderna:

A cultura étnica correspondia supostamente a uma sociedade tradicional [...] [que] manifestava uma cultura espontânea mas isolada com origem numa divisão de trabalho simples e que, por sua vez, reforçava essa divisão do trabalho simples. [...] Assim, as aldeias consistiam em unidades sociais fechadas sobre si mesmas, sem necessidade de relação significativa fora dessa sociedade. Em teoria, a aldeia étnica alcançava a harmonia social através da sua organização produtiva simples. [...] Em teoria, a mente tradicional tendia a responder a laços pessoais, de família e da comunidade e desconfiava das forças burocráticas impessoais, não-familiares e distantes, características da sociedade moderna (Gonzalez: 1997: 160). 
Mas o malogro da integração destes imigrantes não passava de um mito racista. Isto é, a cultura era simplesmente um outro veículo para a discriminação racista.

Os valores culturais considerados não-modernos também persistiam nas comunidades de língua espanhola dos estados anexados ao México, o que levou McWilliams a defender que, apesar de todas as questões de poder, as terras da fronteira não eram um território de hegemonia. Como o grupo de origem anglo-saxónica não tinha conseguido impor a cultura dominante entre esta comunidade do Sudoeste, a diferença deste grupo era intensificada pelas afinidades culturais e linguísticas com os imigrantes mexicanos. A cultura do Sudoeste conservava, pois, uma dinâmica própria que recusava a hierarquia da autoridade, e por isso McWilliams defendia que a fronteira era essencialmente um território de contacto entre culturas: "[n]o Sudoeste, dá-se o encontro das três grandes culturas das Américas: a anglo-americana, a índia e a hispano-americana-mestiça" (1951: 120). As formas que este encontro tomou levam-nos então ao campo recentemente teorizado das contraculturas da modernidade.

McWilliams citava o antropólogo mexicano Manuel Gamio, também especialista em matéria de imigração, que defendia que os mexicanos, na verdade, usavam livremente os aspectos modernos a que tinham acesso na sociedade americana, mas faziam-no de acordo com as suas próprias necessidades. Os mexicanos e seus descendentes abraçavam certas manifestações da modernidade e do "moderno", ao mesmo tempo que resistiam a outras. Segundo Gamio, em termos materiais, poder-se-ia considerar os mexicanos "americanizados", o que podia comprovar-se pela aquisição de aparelhos tecnológicos, que demonstrava que o grupo tinha absorvido com facilidade os valores utilitários da cultura dominante. Já em termos emocionais e intelectuais, a comunidade mexicana vivia em consonância com as tradições locais mexicanas e, por isso, identificava-se com a cultura mexicana. Impedidos de controlar quais os objectos, valores ou comportamentos que a cultura dominante lhes apresentava como "modernos", os imigrantes mexicanos podiam, todavia, decidir o que colher da cultura dominante e em que termos o usar.

O conceito de contraculturas da modernidade foi, na verdade, antecipado por um contemporâneo de McWilliams, o antropólogo cubano Fernando Ortiz, que propôs o termo 'transculturação', ao analisar a cultura afro-cubana, num estudo entitulado Contrapunto cubano, escrito em 1947 (Ortiz, 1995), na altura em que também McWilliams reflectia acerca das relações inter-étnicas. Insatisfeito com o que considerava serem termos desactualizados da integração - a aculturação e a desculturação -, Ortiz elaborou o 
conceito de 'transculturação' como um processo de integração alternativo, que descrevia a selecção e invenção a que recorriam os grupos subordinados ou marginais, na relação que estabeleciam com os materiais que lhes eram transmitidos pela cultura dominante ou metropolitana.

Mas o objectivo de McWilliams não era simplesmente rever ou explicar novamente a especificidade da imigração mexicana; através deste modelo de imigração, ele reexaminou o modelo de modernidade específico da sociedade norte-americana, procurando formas que modificassem o que ele considerava ser uma cultura excessivamente moderna, por assim dizer. Ou seja, uma sociedade obcecada com o culto da racionalidade e do individualismo. De acordo com McWilliams, estas culturas nativas podiam servir de lastro à modernização rápida e alienadora da cultura dos Estados Unidos.

A apreciação que McWilliams fazia das culturas populares não demonstrava qualquer dos receios que os programas de americanização invocavam para a sua erradicação. Com efeito, McWilliams defendeu abertamente que estas culturas deviam ser alimentadas e mantidas, por um lado, para o bem das respectivas populações, e, por outro, pelo muito que elas também tinham para oferecer aos anglo-saxónicos. Os americanos industrializados tinham muito que aprender acerca dos valores de comunidade e solidariedade nas aldeias de adobe do Novo México. Por outro lado, enquanto os programas de assimilação exigiam o apagamento das culturas marginais e a sua transformação em formas da cultura dominante, havia um facto que era ignorado: o quanto a própria cultura dominante já tinha recebido das culturas marginais.

McWilliams voltou a recorrer à história para explicar este "esquecimento". Analisando a formação do Sudoeste moderno, ele fez notar que, socialmente, a cultura hispana tinha conhecido um desenvolvimento maior que a anglo-saxónica, mas tinha acabado por ser suplantada pela aliança dos advogados anglo-saxónicos com os políticos no poder, que tinham manipulado as concessões das terras nas mãos dos colonos espanhóis (1951: 73). Como a comunidade local de língua espanhola valorizava mais a terra pelo uso do que pelo valor económico, não estava bem posicionada em relação aos interesses comerciais para conseguir manter a posse das terras. Apesar desta derrota, que determinara a relação de poder na região, muito havia permanecido da ética não-competitiva que faltava na cultura anglo-saxónica, como os valores de comunidade, coesão social e solidariedade, por exemplo.

McWilliams via, pois, o Novo México como um refúgio de valores residuais dos quais a sociedade norte-americana precisava desesperadamente. A solidariedade e a comunidade também eram valores em evidência nas 
colonias, as comunidades compostas por imigrantes mexicanos, nas franjas das cidades. Estes valores tinham de ser preservados a qualquer custo, pois eram "os últimos vestígios de uma forma de agricultura semi-comunal na América" e este padrão de organização social promovia uma ausência quase completa de distinções de classe social (McWilliams, 1943: 77). A preservação destes modelos e valores culturais não procurava exibir uma raridade de museu, mas sim apresentar um exemplo a seguir, pois tratava-se de "[um] modelo de vida rural que tem muito a recomendar-nos na época presente", escrevia McWilliams (ibid.). Também a língua devia ser preservada, não só porque a língua espanhola, nestas comunidades, permitia reter experiências da infância e adquirir conceitos de transferência, mas porque se tinha tornado também numa parte constituinte da língua inglesa na zona, onde os empréstimos mútuos eram a regra. Mesmo sem o admitir, a cultura dominante já tinha recebido muito das culturas de origem mexicana.

Esta revisão de aspectos interculturais através das culturas não-modernas dos grupos de língua espanhola no Sudoeste não só questiona, assim, o paradigma da modernidade, como requer um entendimento diferente do modernismo na década de 1930-40; um entendimento que não exija, para começar, a a-historicidade como condição de definição. É nesta direcção que têm caminhado estudos recentes, como The Cultural Front. The Laboring of American Culture in the Twentieth Century, de Michael Denning (1997), que propõe que tomemos o acontecimento histórico do crash da Bolsa de valores de Nova Iorque, em 1929, como um ponto de viragem fundamental na arte modernista; não por ter iniciado um movimento artístico diferente, mas por ter exigido a admissão da história e do social no próprio modernismo.

Convém recordar que os estudos clássicos do modernismo, como Modernism, 1890-1930, de Malcolm Bradbury e James McFarlane, defendiam justamente o contrário, que a razão pela qual o modernismo terminara em 1930 fora justamente a Grande Depressão, que trouxera de volta "o determinismo político e económico às ideologias intelectuais" (1991: 52). Isto é, enquanto arte avessa à história, o modernismo não podia tratar assuntos históricos de forma directa. ${ }^{4}$

Para alargar e rearticular o modernismo como uma estrutura discursiva, recorro agora a uma moldura teórica que redefiniu significativamente a relação entre o modernismo e a história, exactamente através do foco na década que Bradbury and McFarlane excluíram por não ser modernista, os

\footnotetext{
${ }^{4}$ Outra referência neste campo é Raymond Williams, que, por sua vez, toma por certo que o “moderno absoluto" teve lugar entre 1890 e 1940 (Williams, 1993: 32).
} 
anos 30. The Cultural Front, de Denning, constrói uma argumentação coesa na defesa de uma revisão dos conceitos do "novo" e do "moderno" como "trabalho" ("labor"). Esta perspectiva muda de forma substancial a qualificação do modernismo - que passa a ser entendido como "modernismo social". Do ponto de vista de Denning, os anos 30 assinalam uma crise no modernismo e na arte de elite que é, por fim, ultrapassada pela necessidade de enfrentar a nova realidade revelada pelo crash de 1929. O facto de a nova geração de escritores e intelectuais que se reuniram em torno da Popular Front serem filhos de imigrantes selou o destino do modernismo. Tomando uma posição ideológica reconhecidamente à esquerda, estes escritores produziram, gradualmente, "uma transformação profunda e duradoura do modernismo e da cultura de massas americanos", através da qual conceitos derivados do campo semântico do trabalho encontraram refúgio no seu imaginário e linguagem (Denning, 1997: xvi).

Nascida nas fileiras da Popular Front, a crítica de Carey McWilliams à modernidade como desenvolvimento leva a sua marca. Ao analisar a exploração, segregação e assimilação dos imigrantes como parte da modernização societal e económica que acompanharam o projecto da modernidade, Carey McWilliams trouxe a lume casos de desenvolvimento desigual que deram origem a contraculturas da modernidade. Se a sociedade dos Estados Unidos tivesse, pelo menos, encontrado uma forma de reavaliar e respeitar estas bolsas de resistência cultural, o seu projecto de modernidade teria sido diferente.

\section{Referências bibliográficas}

Appadurai, Arjun (1998), Modernity at Large: Cultural Dimensions of Globalization. Minneapolis: University of Minnesota Press.

Berman, Marshall (1982), All That Is Solid Melts into Air. The Experience of Modernity. New York: Simon \& Schuster.

Bhabha, Homi K. (1994), The Location of Culture. London: Routledge.

Bradbury, Malcolm; McFarlane, James (orgs.) (1991), Modernism, 1890-1930. London: Penguin.

Denning, Michael (1997), The Cultural Front. The Laboring of American Culture in the Twentieth Century. London: Verso.

Gilroy, Paul (1993), The Black Atlantic. Modernity and Double Consciousness. Cambridge, Mass.: Cambridge UP.

\footnotetext{
5 Michael Denning define aquilo a que chama "the laboring of American culture" como "o uso disseminado de 'trabalho' e dos seus sinónimos na retórica da época" desde o recurso a termos como "movimento operário" ou "proletário", até formas variadas de "trabalho", "indústria" e "esforço físico” ("toil”) (1997: xvi).
} 
Gonzalez, Gilbert G. (1997), "Culture, Language, and the Americanization of Mexican Children”, in Antonia Darder; Rodolfo D. Torres (orgs.), Latinos and Education: A Critical Reader. New York: Routledge,158-173.

Horkheimer, Max; Theodor W. Adorno (1996), Dialektik der Aufklärung: Philosophische Fragmente. Frankfurt am Main: Suhrkamp [1947].

Jameson, Fredric (2000), “Modernism \& Modernity”, conferência na New York University, 6 de Abril.

McWilliams, Carey (1943), “The Forgotten Mexican”, Common Ground, III(3), 65-78.

McWilliams, Carey (1946), Southern California Country. An Island on the Land. New York: Dell, Sloan and Pearce.

McWilliams, Carey (1951), Brothers Under the Skin. Boston: Little, Brown and Company [1943].

McWilliams, Carey (1968), North from Mexico: the Spanish-speaking People of the United States. New York: Greenwood Press [1948].

McWilliams, Carey (1970), The Mexicans in America: A Students' Guide to Localized History. New York: Columbia University Press [1968].

Ortiz, Fernando (1995), Contrapunto cubano del tabaco y del azúcar/Cuban Counterpoint: tobacco and sugar. Trad. Harriet de Onís. Durham: Duke University Press [1947]. Williams Raymond (1993), The Politics of Modernism. Against the New Conformists. London: Verso. 